\title{
Body Dissatisfaction dan Keterkaitannya dengan Subjective Well-Being pada Perempuan Masa Emerging Adulthood
}

\author{
Yemima Carolina Kurnia ${ }^{(1)}$, Sumi Lestari ${ }^{(2)}$ \\ (1),(2) Jurusan Psikologi, Fakultas Ilmu Sosial dan Ilmu Politik, Universitas Brawijaya, Malang, \\ Indonesia
}

\begin{abstract}
In this research, we aimed to examine the relationship between body dissatisfaction and three aspects of subjective well-being, which included life satisfaction, positive affect, and negative affect. Drawing from accidental sampling, participants were 306 women between the ages of 18 and 25 years who were in the period of emerging adulthood and domiciled in Malang, East Java. Designed as a correlational survey, results in this research revealed that high levels of body dissatisfaction corresponded with low levels of life satisfaction and positive affect. Conversely, high levels of body dissatisfaction corresponded with high levels of negative affect. We explain the theoretical implications of these empirical findings in the discussion section, which also highlights the limitations of the present work as well as recommendations for follow-up studies to overcome these limitations.
\end{abstract}

Keywords: body dissatisfaction, life satisfaction, negative affect, positive affect, subjective wellbeing

Penelitian ini bertujuan untuk mengetahui hubungan antara body dissatisfaction dan tiga aspek subjective well-being, yang mencakup kepuasan hidup, afek positif, dan afek negatif. Subjek penelitian adalah 306 perempuan berusia 18-25 tahun yang berada pada masa emerging adulthood dan berdomisili di Kota Malang, Jawa Timur, yang direkrut atas dasar accidental sampling. Studi korelasional dalam penelitian ini menunjukkan bahwa tingginya body dissatisfaction berkaitan dengan rendahnya kepuasaan hidup dan afek positif. Sebaliknya, tingginya body dissatisfaction berkaitan dengan tingginya afek negatif. Implikasi teoritis dari temuan-temuan empiris ini dielaborasi di bagian diskusi, yang juga membahas kelemahankelemahan dalam penelitian ini serta rekomendasi studi lanjutan untuk menutupi kelemahankelamahan tersebut.

Kata kunci: afek negatif, afek positif, body dissatisfaction, kepuasan hidup, subjective well being

MEDIAPSI, 2020, Vol. 6(2), 86-93, DOI: https://doi.org/10.21776/ub.mps.2020.006.02.2

Received: 20-05-2019. Revised: 25-10-2019. Accepted: 07-04-2020. Published online: 07-12-2020

Handling Editor: Intan Rahmawati, Universitas Brawijaya, Malang, Indonesia

*Corresponding author: Yemima Carolina Kurnia, Jurusan Psikologi, Fakultas Ilmu Sosial dan Ilmu Politik, Universitas Brawijaya, Malang, Indonesia.. E-mail: yemimacarolina@ gmail.com

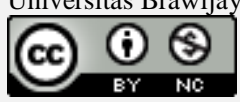

This work is licensed under a Creative Commons Attribution-NonCommercial 4.0 International License.

How to cite this article in accordance with the American Psychological Association (APA) $6^{\text {th }}$ guidelines:

Kurnia, Y. C., \& Lestari, S. (2020). Body dissatisfaction dan keterkaitannya dengan subjective well-being pada perempuan masa emerging adulthood. MEDIAPSI, 6(2), 86-93. https://doi.org/10.21776/ub.mps.2020.006.02.2

\section{Pendahuluan}

Manusia dalam hidupnya selalu mengalami perkembangan mulai dari anak-anak hingga dewasa. Salah satu tahap perkembangan manusia adalah emerging adulthood yaitu masa transisi dari remaja akhir menuju dewasa awal.
Masa ini dimulai sejak seseorang berusia 18-25 tahun (Arnett, 2000). Emerging adulthood memiliki beberapa karakteristik dan karakteristik yang paling menonjol adalah identity explorations (Arnett, 2000). Identity explorations merupakan masa ketika individu 
mengeksplorasi berbagai aspek dalam hidupnya seperti percintaan, pekerjaan, dan pandangan mereka terhadap dunia (Arnett, 2000; Palmeroni dkk., 2020). Pada masa ini individu juga mulai mencoba mengetahui bagaimana individu lain menilai mereka dan melihat apa yang membuat individu tertarik dengan mereka (Arnett, 2014). Emerging adulthood merupakan tahap kehidupan yang rumit secara emosional dan dipenuhi dengan afek positif maupun negatif (Arnett, 2014). Selain itu, pada masa emerging adulthood, eksplorasi mengenai percintaan dan pekerjaan seringkali berakhir dengan kegagalan maupun kekecewaan yang berdampak pada kepuasan hidup individu secara keseluruhan (Arnett, 2014).

Kepuasan hidup, afek positif, dan afek negatif merupakan aspek atau komponen dari subjective well-being. Subjective well-being merupakan istilah ilmiah dari kebahagiaan (Diener \& Ryan, 2009). Subjective well-being (Diener, 2009) merupakan evaluasi seseorang mengenai hidupnya, baik secara afektif maupun kognitif. Evaluasi secara afektif yang dilakukan seseorang terhadap hidupnya dapat dilihat dari afek positif dan afek negatif sedangkan evaluasi kognitif dilihat berdasarkan kepuasan hidup dan juga aspek-aspek penting dalam hidupnya (Diener \& Ryan, 2009). Seseorang yang mengalami lebih banyak afek positif memiliki tingkat subjective well-being yang lebih tinggi dan begitu pula sebaliknya (Diener, 2009). Inglehart (2002) menemukan bahwa perempuan memiliki tingkat subjective well-being yang lebih rendah dibandingkan dengan laki-laki dikarenakan perempuan lebih mudah mengalami emosi negatif dan depresi. Hal ini sejalan dengan argumentasi Diener (2009) yang menyatakan bahwa perempuan lebih sering mengalami emosi positif dan negatif daripada laki-laki.

Penelitian yang dilakukan oleh Donaghue (2009) menunjukkan bahwa kepuasan perempuan terhadap hidup dan pengalaman yang melibatkan afek positif dan negatif berkaitan dengan kepuasan terhadap MEDIAPSI | 2020, Vol. 6, No. 2, 86-93 tubuh mereka. Perempuan pada masa emerging adulthood mendapatkan pesan yang kuat terkait penampilan fisik mereka dari lingkungan sekitar yang berperan dalam membentuk persepsi mereka mengenai tubuhnya (Gillen \& Lefkowitz, 2009). Penampilan fisik yang menarik merupakan pesan dari lingkungan yang sangat penting dan dapat memudahkan seseorang dalam mencapai kesuksesan dalam hal percintaan dan pekerjaan (Gillen \& Lefkowitz, 2009).

Perempuan yang berpenampilan menarik dianggap lebih mudah dalam menjalin hubungan dengan orang lain dan mencari pasangan hidup yang termasuk dalam identity explorations (Arnett, 2014; Hurlock, 2003). Penampilan yang menarik juga menjadi salah satu kriteria yang diperhitungkan saat melamar di dunia kerja karena berhubungan dengan kesempatan kerja yang lebih luas. Walaupun standar penampilan fisik yang menarik dan ideal selalu berubah namun standar yang sering digunakan adalah perempuan yang diharapkan memiliki tubuh langsing dan kulit halus (Grogan, 2008). Bahkan di zaman sekarang banyak media yang memberitakan bahwa penampilan fisik yang menarik jauh lebih penting dibandingkan prestasi (Furman \& Winkles, 2010). Kenyataannya tidak semua perempuan dilahirkan dengan penampilan menarik sehingga terjadi kesenjangan yang membuat perempuan tidak puas terhadap penampilan fisik atau tubuh mereka (Sunartio, Sukamto, \& Dianovinina, 2012). Ketidakpuasan terhadap tubuh membuat mereka khawatir dan tidak bahagia dikarenakan perempuan cenderung lebih sensitif terhadap tekanan akibat stereotip terkait standar tubuh yang ideal. Sebagai konsekuensinya, perempuan memiliki keinginan untuk mengubah bentuk tubuh mereka agar sesuai dengan standar tubuh ideal (Eisenberg, Neumark-Sztainer \& Story, 2003).

Ketidakpuasan terhadap penampilan tubuh disebut juga dengan istilah body dissatisfaction yang merupakan perasaan dan pemikiran negatif seseorang terhadap tubuhnya 
(Grogan, 2008). Body dissatisfaction terjadi ketika ada kesenjangan antara persepsi bentuk tubuh ideal seseorang dengan bentuk tubuh mereka sebenarnya (Niide, Davis, Tse, Derauf, Harrigan, \& Yates, 2011). Penelitian dari Yuanita dan Sukamto (2013) terhadap 150 perempuan menemukan bahwa $74 \%$ remaja perempuan dan $52 \%$ perempuan dewasa awal mengalami body dissatisfaction dengan kategori tinggi akibat perubahan bentuk fisik yang tidak sesuai dengan standar ideal. Hasil penelitian lain yang dilakukan oleh Herawati pada tahun 2003 (dalam Suprapto \& Aditomo, 2007) di antara perempuan berusia 18-25 tahun di Surabaya menunjukkan bahwa sebanyak $40 \%$ perempuan mengalami body dissatisfaction kategori tinggi dan 38\% mengalami body dissatisfaction kategori sedang.

Berdasarkan survei yang dilakukan oleh Napitupulu (2016) pada perempuan di masa emerging adulthood, banyak perempuan yang mengatakan bahwa tubuh yang mereka miliki tidak sesuai dengan harapan. Penilaian ini membuat mereka sulit dalam menjalin relasi dengan orang lain. Mereka merasa bahwa tubuh mereka sangat tidak ideal sehingga membuat mereka malu dalam berkomunikasi dengan lawan jenis. Menurut Brehm (dalam Iswari \& Hartini, 2005), terdapat beberapa faktor penyebab terjadinya body dissatisfaction, yang mencakup standar kecantikan yang tidak tercapai, ketidakpuasan yang mendalam terhadap diri sendiri, dan individu hidup dalam budaya first impression atau kesan pertama. Body dissatisfaction seringkali dikaitkan dengan rasa tidak percaya diri ketika berhubungan dengan lawan jenis dan juga orang lain (Ackard, Kearney-Cooke, \& Peterson, 2000). Body dissatisfaction dapat menyebabkan beberapa kondisi psikologis lain seperti suasana hati yang depresif, kecemasan, kecemasan sosial akibat kondisi fisik dan fobia sosial (Tariq \& Ijaz, 2015).

Borges, Matos, dan Diniz (2013) mengungkapkan bahwa individu yang tidak MEDIAPSI | 2020, Vol. 6, No. 2, 86-93 puas dan memandang tubuh mereka tidak ideal memiliki tingkat well-being yang lebih rendah, salah satunya subjective well-being. Seseorang yang mengalami body dissatisfaction akan merasa tidak puas terhadap hidup mereka (Góngora, 2014). Selain itu, individu yang tidak puas terhadap tubuhnya tidak dapat menjalankan kehidupan secara positif sehingga berdampak pada kepuasan hidup mereka (Sumanty, Sudirman, \& Puspasari, 2018). Sunartio dkk. (2012) menemukan bahwa perempuan yang tidak mampu menerima dan tidak puas terhadap tubuhnya akan merasakan berbagai emosi negatif seperti kecewa, sedih, marah, malu, dan cemas. Temuan ini selaras dengan penelitian Magallares, Jauregui-Lobera, Gamiz-Jimenez, dan Santed (2014) yang membuktikan bahwa perempuan yang tidak puas dengan tubuhnya memiliki afek atau emosi positif lebih rendah dibanding perempuan yang puas dengan tubuhnya.

Berdasarkan uraian di atas, penelitian mengenai body dissatisfaction dan subjective well-being pada perempuan sangat menarik untuk dikaji lebih lanjut. Atas dasar landasan teori dan temuan-temuan empiris yang terkait, penelitian ini mengajukan tiga hipotesis. Pertama, body dissatisfaction berkorelasi signifikan ke arah negatif dengan kepuasan hidup dimana semakin tinggi body dissatisfaction maka semakin rendah kepuasan hidup (Hipotesis 1). Kedua, body dissatisfaction berkorelasi signifikan ke arah negatif dengan afek positif dimana semakin tinggi body dissatisfaction maka semakin rendah afek positif (Hipotesis 2). Ketiga, body dissatisfaction berkorelasi signifikan ke arah positif dengan afek negatif dimana semakin tinggi body dissatisfaction maka semakin tinggi juga afek negatif (Hipotesis 3).

\section{Metode}

\section{Partisipan dan desain penelitian}

Partisipan dalam penelitian ini adalah 306 perempuan pada masa emerging adulthood yang berusia 18-25 tahun di Kota Malang. 
Pengambilan sampel dilakukan dengan menggunakan teknik non probability sampling yaitu accidental sampling. Penelitian ini merupakan penelitian yang menggunakan pendekatan kuantitatif korelasional yang bertujuan untuk mengetahui peran body dissatisfaction dalam menjelaskan aspek-aspek subjective well-being, yang terdiri dari kepuasan hidup, afek positif, dan afek negatif.

\section{Prosedur dan pengukuran}

Data pada penelitian ini diambil dengan menggunakan skala atau kuesioner, yang disebarkan di tempat-tempat umum seperti mall, alun-alun, dan lain lain. Instrumen penelitian yang digunakan pada penelitian ini terdiri dari skala body dissatisfaction serta skala subjective well-being yang mencakup sub-skala satisfaction with life (SWLS; Diener, Emmons, Larsen, \& Griffin, 1985), sub-skala afek positif (The Scale of Positive and Negative Experience: SPANE-P; Diener dkk., 2009) dan sub-skala afek negatif (The Scale of Positive and Negative Experience: SPANE-N; Diener dkk., 2009). Skala body dissatifaction terdiri dari 30 aitem, dimodifikasi dari penelitian Ardillah (2017) yang mengacu pada dimensi body dissatisfaction dari Rosen dan Reiter (1996). Uji coba yang dilakukan pada 75 mahasiswi Universitas Brawijaya menunjukkan bahwa alat ukur tersebut reliabel dengan koefisien reliabilitas Cronbach alpha $(\alpha)$ sebesar .94. Sementara itu, peneliti melakukan transadaptasi sub-skala kepuasaan hidup serta sub-skala afek positif dan afek negatif dengan menerjemahkan aitem-aitem skala asli ke dalam Bahasa Indonesia. Hasil uji coba menunjukkan bahwa sub-skala kepuasaan hidup memiliki koefisien reliabilitas sebesar .82, sementara sub-skala afek positif memiliki koefisien reliabilitas sebesar .84 dan sub-skala afek positif memiliki koefisien reliabilitas sebesar .75 .

\section{Hasil}

Sebelum melakukan uji hipotesis, peneliti terlebih dahulu melakukan uji asumsi. normalitas dengan menggunakan teknik Komolgorov-Smirnov. Hasil uji ini ditampilkan dalam Tabel 1.

Sebagaimana bisa dilihat pada Tabel 1, hasil uji normalitas menunjukkan bahwa hanya body dissatisfaction yang memiliki distribusi normal, sementara variabel-vaiabel lainnya (kepuasan hidup, afek postif, dan afek negatif) tidak terdistribusi secara normal.

Tabel 1. Hasil Uji Normalitas

\begin{tabular}{lccc}
\hline \multicolumn{1}{c}{ Variabel } & $K-S$ & $p$ & Keterangan \\
\hline $\begin{array}{l}\text { Body } \\
\text { dissatisfaction }\end{array}$ & 0.04 & .200 & Normal \\
$\begin{array}{l}\text { Kepuasaan } \\
\text { hidup }\end{array}$ & 0.07 & .001 & Tidak normal \\
$\begin{array}{l}\text { Afek positif } \\
\text { Afek negatif }\end{array}$ & 0.10 & $<.001$ & Tidak normal \\
Keterangan: $K-S=$ Kolmogorov-Smirnov; $p=$ nilai signifikansi.
\end{tabular}

Mempertimbangkan bahwa sebagian besar variabel dalam penelitian ini tidak terdistribusi secara normal, peneliti menggunakan teknik korelasional Spearman Rho dengan bantuan SPSS versi 24.

Hasil uji hipotesis menunjukkan bahwa body dissatisfaction berkorelasi signifikan ke arah negatif dengan kepuasan hidup, $r=-.29, p$ $<.001$. Hasil kuadrat nilai $r$ adalah sebesar .08 , yang menunjukkan bahwa body dissatisfaction memberikan sumbangan sebesar $8 \%$ dalam menjelaskan tingkat kepuasan hidup. Dengan hasil ini Hipotesis 1 diterima.

Sementara itu, body dissatisfaction ditemukan berkorelasi signifikan ke arah negatif dengan afek positif, $r=-.24, p<.001$. Nilai kuadrat $r$ adalah sebesar .06 , yang mengandung arti bahwa body dissatisfaction menjelaskan afek positif sebesar $6 \%$. Hasil ini juga mendukung Hipotesis 2. Hasil terakhir menunjukkan bahwa body dissatisfaction berkorelasi signifikan ke arah positif dengan afek negatif, $r=.259, p<.001$, dengan nilai $r^{2}$ sebesar .07. Hasil ini dengan demikian mendukung Hipotesis 3 dan menunjukkan 
bahwa body dissatisfaction mampu menjelaskan variasi afek negatif sebesar $7 \%$.

\section{Diskusi}

Penelitian ini bertujuan untuk menguji hubungan antara body dissatisfaction dengan subjective well-being pada perempuan masa emerging adulthood. Hasil uji korelasi menunjukkan bahwa, mendukung hipotesishipotesis yang diajukan, body dissatisfaction memiliki hubungan secara signifikan dengan ketiga aspek dari subjective well-being, yaitu kepuasan hidup, afek positif, dan afek negatif. Body dissatisfaction memiliki hubungan negatif dengan kepuasan hidup dan afek positif. Body dissatisfaction memiliki hubungan positif dengan afek negatif.

Atas dasar hasil-hasil penelitian di atas, ditemukan bahwa body dissatisfaction menjadi salah satu faktor yang memengaruhi kepuasan hidup pada perempuan di masa emerging adulthood. Perempuan di masa emerging adulthood yang mengalami body dissatisfaction akan terpaku pada kekurangan pada tubuh mereka (Rosen \& Reiter, 1996), sehingga mereka merasa tidak puas juga terhadap aspek-aspek dalam hidup mereka. Ketidakpuasaan ini berdampak pada kepuasan hidup secara keseluruhan. Korelasi negatif antara body dissatisfaction dan subjective wellbeing bermakna bahwa apabila body dissatisfaction meningkat maka kepuasan hidup menurun. Pola hubungan ini sesuai dengan pernyataan Góngora (2014) bahwa seseorang yang mengalami body dissatisfaction akan merasa tidak puas terhadap hidup mereka. Selain itu, hasil penelitian ini juga sejalan dengan penelitian Sumanty dkk. (2018). Mereka menemukan bahwa individu yang tidak puas terhadap tubuhnya tidak dapat menjalani kehidupan secara positif sehingga berdampak pada kepuasan hidup mereka.

Penelitian ini juga menunjukkan bahwa body dissatisfaction dan afek positif memiliki hubungan ke arah negatif. Korelasi ini menunjukkan bahwa jika body dissatisfaction MEDIAPSI | 2020, Vol. 6, No. 2, 86-93 meningkat maka afek positif yang dialami perempuan di masa emerging adulthood menurun, begitu pula sebaliknya. Hubungan antara body dissatisfaction dan afek positif dari penelitian ini sesuai dengan hasil penelitian dari Magallares dkk. (2014) yang menunjukkan bahwa wanita yang tidak puas dengan tubuhnya memiliki afek positif yang lebih rendah dibanding wanita yang puas dengan tubuhnya. Pola hubungan ini disebabkan karena perempuan di masa emerging adulthood yang mengalami body dissatisfaction akan berfokus pada kekurangan atau ketidaksempurnaan pada tubuhnya sehingga membuat mereka mengalami emosi positif lebih sedikit. Hasil penelitian ini sesuai dengan pernyataan Donaghue (2009) bahwa kepuasan perempuan terhadap hidup dan pengalaman yang melibatkan afek positif berkaitan dengan kepuasan mereka terhadap tubuhnya.

Afek positif dan afek negatif merupakan dua hal yang saling berkaitan (Diener, 2009). Selain memiliki hubungan dengan afek positif, body dissatisfaction juga memiliki hubungan dengan afek negatif pada perempuan di masa emerging adulthood. Perempuan yang tidak puas terhadap tubuh mereka akan merasa tidak nyaman dengan tubuh yang mereka miliki, sehingga menimbulkan berbagai emosi negatif terkait bentuk tubuh mereka. Hal ini selaras dengan survei yang dilakukan Napitupulu (2016) yang melaporkan bahwa di masa emerging adulthood, banyak perempuan yang mengatakan bahwa tubuh yang mereka miliki tidak sesuai dengan harapan dan membuat mereka sulit dalam menjalin relasi dengan orang lain. Mereka merasa bahwa tubuh mereka terlalu berisi atau tambun sehingga membuat mereka malu dalam berkomunikasi dengan lawan jenis. Hasil penelitian ini juga sejalan dengan temuan Sunartio dkk. (2012), yang menunjukkan bahwa perempuan yang tidak puas terhadap tubuh mereka akan merasakan berbagai emosi negatif seperti kecewa, sedih, marah, malu dan cemas. Selanjutnya, Tariq dan Ijaz (2015) menyatakan bahwa body 
dissatisfaction dapat memicu depresi, fobia sosial, dan kecemasan sosial atas kondisi fisik yang dimiliki.

Mengacu pada hasil-hasil penelitian ini, bisa disimpulkan bahwa body dissatisfaction dan subjective well-being memiliki hubungan yang signifikan. Hubungan ini secara lebih spesifik menggambarkan bahwa individu dengan tingkat body dissatisfaction yang tinggi memiliki tingkat subjective well-being yang lebih rendah dibanding individu dengan tingkat body dissatisfaction yang rendah.

Penelitian ini memiliki sejumlah kelemahan, yang bisa diperbaiki pada penelitian-penelitian lanjutan. Kelemahan pertama terkait dengan sebaran aitem dalam skala body dissatisfaction yang kurang berimbang. Peneliti dengan demikian menyarankan agar studi lanjutan lebih memperhatikan alat ukur yang digunakan agar sebaran aitem pada tiap dimensi berimbang. Kelemahan kedua terkait dengan faktor-faktor lain yang dapat mempengaruhi subjective wellbeing seseorang di luar body dissatisfaction, yang tidak diukur dalam penelitan ini. Studi lanjutan dengan demikian bisa mengukur faktor-faktor tersebut, yang mencakup, misalnya, pendapatan, usia, jenis kelamin, pekerjaan, pendidikan, agama, status pernikahan, dan keluarga (Diener, 2009). Studi lanjutan juga bisa menguji kepribadian (Grant, Langan-Fox, \& Anglim, 2009), dukungan sosial (Gallagher \& Vella-Brodrick, 2008), serta orientasi budaya (Utsey, Hook, Fischer, \& Belvet, 2008) sebagai faktor-faktor selain faktor demografis yang juga berpengaruh terhadap subjective well-being.

\section{Daftar Pustaka}

Ackard, D. M., Kearney-Cooke, A., \& Peterson, C. B. (2000). Effect of body image and self-image on women's sexual behaviors. International Journal of Eating Disorders, 28(4), 422-429. https://doi.org/10.1002/1098108X(200012)28:4\%3C422::AID-
EAT10\%3E3.0.CO;2-1

Ardhillah, A. (2017). Hubungan antara body dissatisfaction dengan kecemasan pada ibu hamil (Skripsi tidak dipublikasikan). Jurusan Psikologi, Fakultas Ilmu Sosial dan Ilmu Politik, Universitas Brawijaya, Malang, Indonesia.

Arnett, J. J. (2000). Emerging adulthood: A theory of development from the late teens through the twenties. American Psychologist, 55(5), 469-480. https://doi.org/10.1037//0003066X.55.5.469

Arnett, J. J. (2014). Emerging adulthood: The winding road from the late teens through the twenties. New York: Oxford University Press.

Borges, A., Matos, M. G. De, \& Diniz, J. A. (2013). Body image and subjective wellbeing in Portuguese adolescents. Spanish Journal of Psychology, 17(16), 1-12. https://doi.org/10.1017/sjp.2013.24

Diener, E. (2009). Subjective well-being. Social Indicator Research, 37, 11-58. https://doi.org/10.1007/978-90-481-2350$6 \_2$

Diener, E., Emmons, R. A., Larsen, R. J., \& Griffin, S. (1985). The satisfaction with life scale. Journal of Personality Assesment, $\quad 49(1), \quad 71-75$. https://doi.org/10.1207/s15327752jpa4901 -13

Diener, E., \& Ryan, K. (2009). Subjective wellbeing: A general overview. South African Journal of Psychology, 39(4), 391-406. https://doi.org/10.1177/008124630900402

Diener, E., Wirtz, D., Tov, W., Kim-Prieto, C., Choi, D., Oishi, S., \& Biswar-Diener, R. (2009). New well-being measures: Short scales to access flourishing and positive and negative feelings. Social Indicator Research, 97, 143-156. https://doi.org/10.1007/s11205-009-9493$\mathrm{y}$

Donaghue, N. (2009). Body satisfaction, sexual self-schemas and subjective well-being in 
women. Body Image, 6, 37-42. https://doi.org/10.1016/j.bodyim.2008.08.0 02

Eisenberg, M. E., Neumark-Sztainer, N., \& Story, M. (2003). Association of weightbased teasing and emotional well-being among adolescents. Journal of Adolescent Health, 32(2), 733-738. https://doi.org/10.1016/S1054-

139X(02)00610-9

Furman, W., \& Winkles, J. K. (2010). Predicting romantic involvement, relationship cognitions, and relationship qualities from physical appearance, perceived norms, and relational styles regarding friends and parents. Journal of Adolescence, 33(6), 827-836. https://doi.org/10.1016/j.adolescence.2010. 07.004

Gallagher, E. N., \& Vella-Brodrick, D. A. (2008). Social support and emotional intelligence as predictors of subjective well-being. Personality and Individual Differences, 44(7), 1551-1561. https://doi.org/10.1016/j.paid.2008.01.011

Gillen, M. M., \& Lefkowitz, E. S. (2009). Emerging adults' perceptions of messages about physical appearance. Body Image, 6, 178-185.

https://doi.org/10.1016/j.bodyim.2009.02.0 02

Góngora, V. C. (2014). Satisfaction with life, well-being, and meaning in life as protective factors of eating disorder symptoms and body dissatisfaction in adolescent. Eating Disordes, 2, 435-449. https://www.doi.org/10.1080/10640266.20 14.931765

Grant, S., Langan-Fox, J., \& Anglim, J. (2009). The big five traits as predictors of subjective and psychological wellbeing. Psychological Reports, 105(1), 205231.

https://doi.org/10.2466\%2FPR0.105.1.205 $-231$

Grogan, S. (2008). Body Image: Understanding MEDIAPSI | 2020, Vol. 6, No. 2, 86-93 body image in man, women, and children. New York: Routledge.

Hurlock, E. B. (2003). Psikologi perkembangan: Suatu pendekatan sepanjang rentang kehidupan. Jakarta: Erlangga.

Inglehart, R. (2002). Gender, aging, and subjective well-being. International Journal of Comparative Sociology, 43(35), 391-408. https://doi.org/10.1177\%2F002071520204 300309

Iswari, D., Hartini, N., \& Unair, F. P. (2005). Pengaruh pelatihan dan evaluasi self-talk terhadap penurunan tingkat bodydissatisfaction. Journal Unair Surabaya, 7(3), 2310-7945. Diakses dari http://www.journal.unair.ac.id/downloadfullpapers-Artike1\%20penelitian\%20ditanurul.pdf

Magallares, A., Jauregui-Lobera, I., GamizJimenez, N., \& Santed, M. A. (2014). Subjective well-being in a sample of women with eating disorders. The Psychological Record, 64(04), 769-776. https://doi.org/10.1007/s40732-014-0043$\mathrm{x}$

Napitupulu, R. T. M. (2016). Hubungan antara body dissatisfaction dengan psychological well-being pada emerging adulthood (Skripsi, Universitas Surabaya, Surabaya, Indonesia). Diakses dari http://repository.ubaya.ac.id/28863/

Niide, T. K., Davis, J., Tse, A. M., Derauf, C., Harrigan, R. C., \& Yates, A. (2011). Body ideals and body dissatisfaction among a community sample of ethnically diverse adolescents on Kauai, Hawaii. Hawaii $J$ Public Health, 3(1), 1-7. http://dx.doi.org/10.1016/j.bodyim.2012.0 9.001

Palmeroni, N., Claes, L., Verschueren, M., Bogaerts, A., Buelens, T., \& Luyckx, K. (2020). Identity distress throughout adolescence and emerging adulthood: Age trends and associations with exploration 
and commitment processes. Emerging Adulthood, 8(5), 333-343. https://doi.org/10.1177\%2F216769681882 1803

Rosen, J. C., \& Reiter, J. (1996). Development of the body dysmorphic disorder examination. Behaviour Research and Therapy, 34(9), 755-766. https://doi.org/10.1016/00057967(96)00024-1

Sumanty, D., Sudirman, D., \& Puspasari, D. (2018). Hubungan religiusitas dengan citra tubuh pada wanita dewasa awal. Jurnal Psikologi Islam dan Budaya 1(1), 9-28. https://doi.org/10.15575/jpib.vlil.2076

Sunartio, L., Sukamto, M. E., \& Dianovinina, K. (2012). Social comparison dan body dissatisfaction pada wanita dewasa awal. HUMANITAS (Jurnal Psikologi Indonesia), $\quad$ 9(2). 157-168. http://dx.doi.org/10.26555/humanitas.v9i2. 342

Suprapto, M. H. \& Aditomo, A. (2007). Aku dan dia, cantik mana? Perbandingan sosial, body dissatisfaction \& objektivikasi diri. Anima, 2(2), 186-191. Diakses dari http://repository.ubaya.ac.id/25251/

Tariq, M., \& Ijaz, T. (2015). Development of body dissatisfaction scale for university students. Pakistan Journal of Psychological Research, 30(02), 305-322. Diakses dari https://www.pjprnip.edu.pk/index.php/pjpr /article/view/308

Utsey, S. O., Hook, J. N., Fischer, N., \& Belvet, B. (2008). Cultural orientation, ego resilience, and optimism as predictors of subjective well-being in African Americans. The Journal of Positive Psychology, 3(3), 202-210. https://doi.org/10.1080/174397608019996 10

Yuanita, H. \& Sukamto, M. E. (2013). Fenomena body dissatisfaction pada perempuan anggota fitness centre. Jurnal Psikologi Teori \& Terapan, 4(1), 12-23. http://dx.doi.org/10.26740/jptt.v4n1.p1223 